\title{
ROUGH-RULES-BASED DECISION MODEL FOR MULTIPLE OBJECTIVES PORTFOLIO OPTIMIZATION
}

\begin{abstract}
This study aims to propose a novel hybrid approach for the multiple objectives portfolio optimization problem. Two types of heterogeneous inputs are infused to construct a multiple objectives optimization model: (1) a group of rough decision rules for selecting stocks with superior financial prospects (induced from historical data by rough machine learning) and (2) the preferential structure from decision makers (collected by questionnaires). Five blue chip stocks from the Taiwan stock market are illustrated and examined in this work, from 2010 to 2015; in addition, the prevailing ANP-based method for multiple objectives portfolio optimization is compared with the proposed approach.
\end{abstract}

Keywords: portfolio optimization, multiple objectives decision-making (MODM), multiple rules-based decision-making (MRDM), dominance-based rough set approach (DRSA), DEMATEL-based analytic network process (DANP).

\section{Introduction}

The key research question of portfolio optimization in multiple criteria decision-making (MCDM) is how to get closer to a decision maker's risk preference structure under a set of given constraints. The modeling of preference structure is rooted from multiple attributes utility theory (MAUT), which focuses on collecting the opinions of decision makers (DMs) to synthesize a preference-weighted goal for optimization. Various methods, such as AHP and ANP, have been adopted to identify the relative importance of each individual goal of DMs. Nevertheless, this type of research mainly use the historical prices of the selected stocks to calculate the expected returns and risk of a portfolio; the financial performance of individual stock is not considered in this kind of research; a portfolio optimization model that can consider the financial prospects of stocks is underexplored.

To bridge this research gap, the present work proposes a two-stage hybrid model to consider the quarterly financial performance (prospects) of each stock at first, and a DEMATEL-based ANP (DANP) method (Liou and Tzeng, 2013) is adopted to assess DMs' risk preference structure on multiple objectives portfolio optimization, in the next. That is to say, this hybrid model is enhanced by rough machine learning to identify the candidates (i.e., certain stocks from a selected pool) that might have superior returns in the subsequent quarter, and the risk preference based on the DANP influential weights is considered for this portfolio optimization problem. The devised optimization model will be rebalanced in each quarter based on the released financial reports and the price movements of stock market.

The proposed approach has two main advantages on portfolio optimization: (1) induce transparent financial knowledge regarding stock selection and (2) use the obtained decision rules and DANP weights to optimize a portfolio considering the complex risk preference of a DM. In a fast changing, imprecise and complex financial market, how to make informed prudent decisions would have high value in practice; it can also be regarded as the integration of multiple rules-based decision-making (MRDM), multiple attribute decision-making (MADM), and MODM on solving a financial problem. 
ISAHP Article: A Style Guide for Paper Proposals To Be Submitted to the International Symposium on the Analytic Hierarchy Process 2016, London, U.K.

\section{Literature Review}

The typical studies of portfolio optimization are based on the classical work of Markowitz (1952). In the context of MODM research, some more factors/criteria are also incorporated, such as the suitability of equities for a DM (Gupta, et al, 2014). Only few studies attempted to analyze the financial prospects of stocks while optimizing a portfolio in MODM; for example, Huang et al. (2015) developed a hybrid DEA-MODM model to analyze the relative financial efficiency of stocks by DEA. However, in a fast changing stock market, the relative efficiency of stocks will change over time; in addition, the linkage/relation between financial efficiency and the subsequent return of a stock is neither examined nor confirmed in that DEA-MODM model.

\section{Hypotheses/Objectives}

There are two major objectives in here: (1) explore the rough financial knowledge on selecting stocks and (2) optimize a portfolio considering the financial prospects of stocks and the risk preference structure of a DM.

\section{Research Design/Methodology}

At first, the requested key financial indicators - 18 financial ratios in five dimensionsfrom the Taiwan Stock Exchange (TWSE) are used for inducing rough financial knowledge. In the next, the criteria of expected return and risk in the short-, middle-, and long-terms are combined with the liquidity criterion (i.e., seven criteria) for forming a DANP model to identify the risk preference structure of a DM. Finally, the DANP weighted goal, including multiple objectives, is optimized for forming a portfolio.

\section{Data/Model Analysis}

Five blue-chip stocks from the Taiwan stock market are the target candidates for forming a portfolio; the whole IT stocks' historical data from 2010 to 2014 are used as the training set to induce rough decision rules. A seasoned investor is invited for collecting his risk preference structure by the DANP method. A portfolio will be optimized (rebalanced) once the latest financial reports are released in each quarter of 2015, and the five candidates will be selected by the rough decision rules to form an optimized portfolio.

\section{Limitations}

This model is based on the assumption that the financial performance will cause consistent or similar impact on the subsequent return of a stock. Also, exogenous influences (e.g., financial crises) are not considered in here.

\section{Conclusions}

This study proposes a new approach to infuse two types of transparent inputs - a set of rough decision rules for stock selection and the risk preference structure of a DM-for solving the multiple objectives portfolio optimization problem.

\section{Key References}

Liou, J.J., \& Tzeng, G.H. (2012). Comments on "Multiple criteria decision making (MCDM) methods in economics: an overview". Technological and Economic Development of Economy, 18(4), 672-695.

Markowitz, H.M. (1952). Portfolio selection. The Journal of Finance 7 (1), 77 - 91.

Gupta, P., Mehlawat, M.K., Inuiguchi, M., \& Chandra, S. (2014). Suitability considerations in multi-criteria fuzzy portfolio optimization. In: Fuzzy Portfolio Optimization (pp. 187-253). Springer Berlin Heidelberg.

Huang, C.Y., Chiou, C.C., Wu, T.H., \& Yang, S.C. (2015). An integrated DEA-MODM methodology for portfolio optimization. Operational Research, 15(1), 115-136.

International Symposium on the

2

London, U.K.

Analytic Hierarchy Process

August 4 - August 7, 2016 